\title{
Effect of heat treatment on properties of steam cured fly ash-lime compacts
}

\author{
S MAITRA*, S DAS, A K DAS ${ }^{\dagger}$ and A BASUMAJUMDAR ${ }^{\dagger}$ \\ Government College of Engineering and Ceramic Technology, WB University of Technology, Kolkata 700 010, India \\ ${ }^{\dagger}$ Department of Chemical Technology, University of Calcutta, Kolkata 700 009, India
}

MS received 4 June 2005

\begin{abstract}
Four different varieties of class $F$ fly ashes, collected from different sources from the state of West Bengal (India) were mixed with lime in $9: 1 \mathrm{wt}$ ratio, followed by compaction of the mixes. The compacts were subjected to steam curing to develop an optimum strength by the reaction between fly ash and lime. The steam cured compacts were heated at different elevated temperatures and free lime content, compressive strength, bulk density and water absorption tendency of these compacts were measured and FTIR spectral changes were studied as a function of the heating temperatures. Kinetics of thermal dehydration of the compacts was also studied from thermogravimetric measurements under non-isothermal condition to ascertain the order of dehydration process and the associated activation energy.
\end{abstract}

Keywords. Fly ash-lime; compacts; curing; heat treatment.

\section{Introduction}

Fly ash has a tendency to react with lime to form different lime bearing silicates/aluminates hydrates due to its pozzolanic properties. These hydrates possess cementitious properties and are responsible for the development of strength in fly ash-lime compacts, which are used as structural products, like bricks and blocks suitable for use in masonry works just like common burnt clay bricks.

Different researchers worked on the fly ash based structural products. Song et al (1996) studied the manufacture and properties of coal fly ash-clay bodies. They suggested that bulk substitution of coal fly ash for clay in building bricks and tiles was possible because the chemical composition of fly ash was mostly $\mathrm{Al}_{2} \mathrm{O}_{3}$ and $\mathrm{SiO}_{2}$ and its properties were very similar to those of clays. Kumar (2002) made a perspective study on fly ash-lime-gypsum bricks and hollow blocks for low cost housing development. It was observed that these bricks and hollow blocks had sufficient strength for their use in low cost housing development. It was also observed that the hot water curing leads to a greater degree of hardening and higher strength, earlier compared to ordinary water curing. Zhu (1994) analysed effects of solidifiers (such as lime, cement, cement-lime and lime-gypsum), process parameters (including raw materials and compacting pressure) and production processes on properties of fly ash silicate products. Muntcan et al (1987) reported that the physicomechanical properties of autoclaved siliceous limestone

*Author for correspondence (maitra_s@ @snl.net) with $10-30 \%$ fly ash was superior compared to the product obtained from lime and sand only under similar condition. Barbier (1986) studied on the possible uses of coal fly ash in brick industry with respect to the availability and characteristics of fly ash. Tsunematsu et al (1987) observed that in hydrothermal reaction of fly ash with lime and gypsum at $180^{\circ} \mathrm{C}$ a good correlation existed between $\mathrm{Al} /(\mathrm{Si}+\mathrm{Al})$ and ratio of glass phase and the yield of hydrogarnet. Ma and Brown (1997) observed that the variation in reactivity of fly ash with $\mathrm{Ca}(\mathrm{OH})_{2}$ and $\mathrm{CaSO}_{4} \cdot 2 \mathrm{H}_{2} \mathrm{O}$ in hydrothermal reaction depends on the presence of $\mathrm{Ca}(\mathrm{OH})_{2}$ or $\mathrm{CaSO}_{4} \cdot 2 \mathrm{H}_{2} \mathrm{O}$. Wang et al (1996) studied on the reaction mechanism of fly ashlime-water system and proposed a model of the reaction. Ma and Zhao (1993) developed a method for the manufacture of fired hollow blocks of fly ash with adequate mechanical strength. Liu et al (1994) worked on press forming of sintered hollow brick with high fly ash content and related the rate of temperature rise and highest sintering temperature to the fly ash content of the bricks. Basumajumdar et al (2005) developed correlation between free lime remaining in steam cured and water cured fly ash-lime compacts under equilibrium conditions with the chemical composition of fly ash.

Though, a lot of work has been done in different laboratories on the fly ash-lime compact systems, but a scanty attention has so far been paid on the thermal stability of these compacts. In the present investigation, therefore, steam cured fly ash-lime compacts were subjected to heat treatment to ascertain the thermal stability and related changes by measuring free $\mathrm{CaO}$ content, compressive strength, studying the FT-IR spectroscopy and 
determining the kinetic parameters under non-isothermal conditions from the DTGA studies.

\section{Experimental}

In the present investigation, four different varieties of class F fly ash samples from different power plants of West Bengal (India) were collected following IS:1528-1974, Part-VII specification. Chemical analyses of the ash samples were carried out following sodium carbonate fusion process. For the measurement of bulk density of the ash samples a fixed volume of the sample was taken in a measuring cylinder, which was tapped for sufficient number of times for thorough packing and its weight was measured. Blain's air permeability apparatus was used for measuring the surface area of the ash sample. Specific gravity of the ash samples was measured by pycnometer following specification IS: 1528-1974, Part-IX. All the physicochemical properties of the ash samples are given in table 1 . Pulverized lime with high percentage of $\mathrm{CaO}$ (> $80 \mathrm{wt} \%)$ and considerable surface area $\left(10,800 \mathrm{~cm}^{2} / \mathrm{g}\right.$ ) was used in the present investigation. The test compacts were prepared by mixing fly ash and lime in the weight ratios of $9: 1$ in a laboratory mixer with sufficient mixing time $(6 \mathrm{~h})$ to ensure thorough mixing. The mix thus obtained was compacted with $5 \%$ moisture with a hydraulic press at a pressure of $250 \mathrm{~kg} / \mathrm{cm}^{2}$ (Basumajumdar et al 2005). The test compacts were steam cured in an autoclave at an average steam pressure and temperature of $2.5 \mathrm{~kg} / \mathrm{cm}^{2}$ and $120^{\circ} \mathrm{C}$ for a period of $10 \mathrm{~h}$, respectively (Basumajumdar et al 2005). The free lime content in the test specimens was measured chemically using the procedure described by Hanna et al (1938, 1939).

\section{Results and discussion}

Fly ash: lime in the ratio of $9: 1$ was used in the present investigation to study the possibility of the maximum utilization of fly ash. Various types of calcium silicate and calcium alumino-silicate hydrates are formed by the reaction between fly ash and lime (Watt and Thorne 1996). When the fly ash-lime compacts were subjected to elevated temperatures, water molecules associated with the structures were progressively lost depending on the binding energy of the system. This loss of water affected the physico-mechanical properties of fly ash-lime compacts. To study this effect the free lime content and compressive strength of the fly ash-lime compacts were measured as a function of heating temperature.

\subsection{Effect of heating on free lime content}

The free lime content of the fly ash-lime compacts did not change significantly up to a heating temperature of $300^{\circ} \mathrm{C}$ and after that it suddenly increased as evident from figures 1 and 2. It suggested that water molecules were mostly lost up to a period of $300^{\circ} \mathrm{C}$, and the calcium silicate/aluminosilicate bonds mostly remained unaffected within this temperature range. A rapid increase in the free lime concentration indicated the dissociation of calcium silicate/aluminate bonds, which probably started after a temperature of $300^{\circ} \mathrm{C}$. The free lime generation in the heated masses increased from $300-450^{\circ} \mathrm{C}$ and after that it started to increase from a heating temperature of $500{ }^{\circ} \mathrm{C}$. Therefore, the calcium silicate hydrate of two different ranges of stability was formed in the cured fly ash-lime compacts.

\subsection{Effect of heating on compressive strength}

With heating the compressive strength increased up to a period of $250^{\circ} \mathrm{C}$ and after approximately $350^{\circ} \mathrm{C}$, the com-

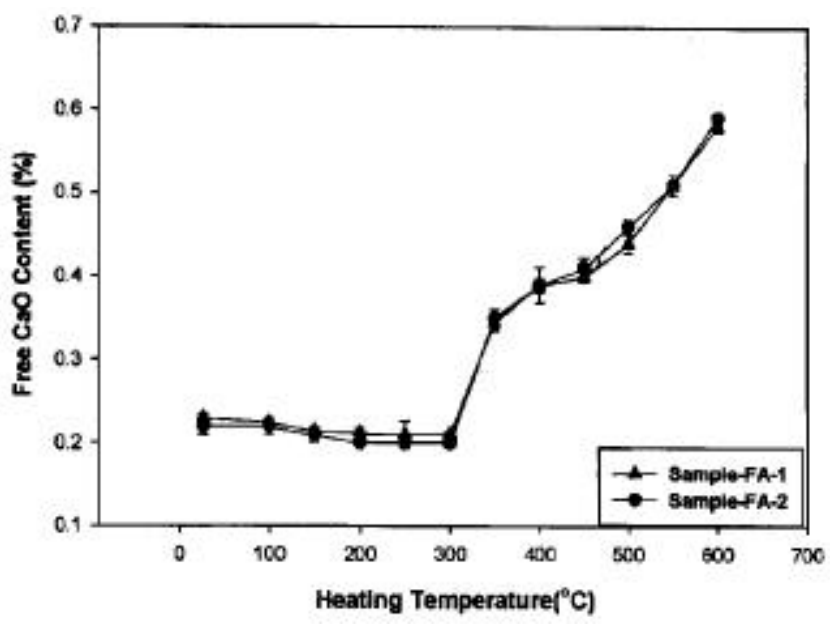

Figure 1. Effect of heating on the free $\mathrm{CaO}$ content of steam cured fly ash-lime compacts.

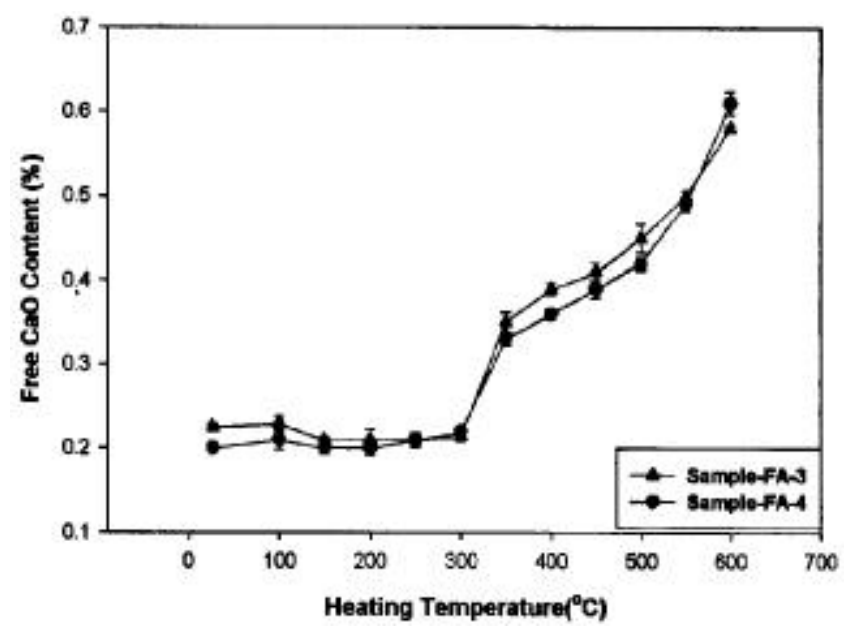

Figure 2. Effect of heating on the free $\mathrm{CaO}$ content of steam cured fly ash-lime compacts. 
pressive strength decreased with the increase in heating temperature as evident from figures 3 and 4 . Within this heating temperature, concentration of free lime generated from the lime-fly ash compacts did not change significantly, but water molecules got removed from the hydrates within this temperature range. Loss of these water molecules did not change the compressive strength of the compacts significantly. Beyond $350^{\circ} \mathrm{C}$, the compressive strength decreased due to the breakage of calcium silicate/ calcium aluminate hydrates.

\subsection{Change in FT-IR spectroscopy of compact during heating}

With the increase in the heating temperature, $\%$ transmission of the IR radiation increased (figures $5 \mathrm{a}-\mathrm{d}$ ). In the

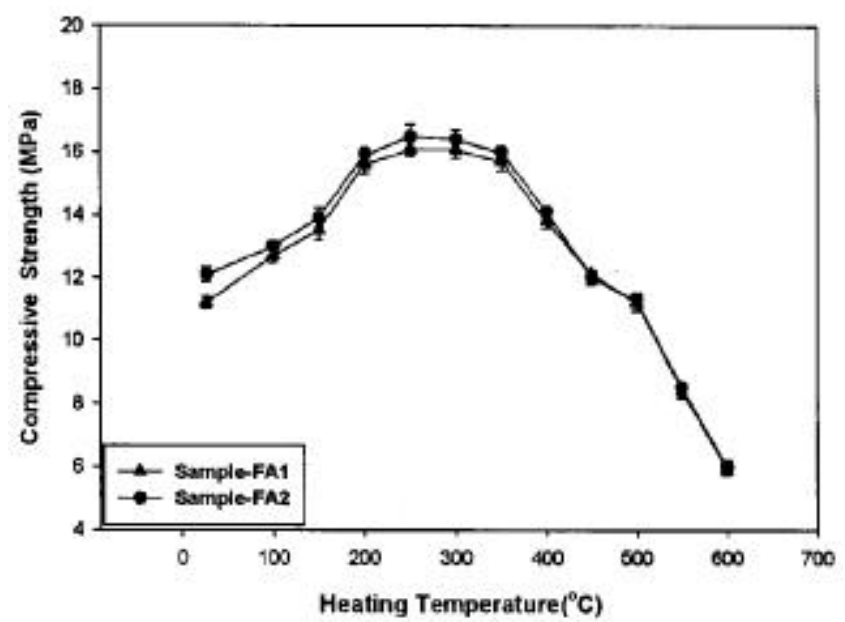

Figure 3. Effect of heating on the compressive strength of steam cured fly ash-lime compacts.

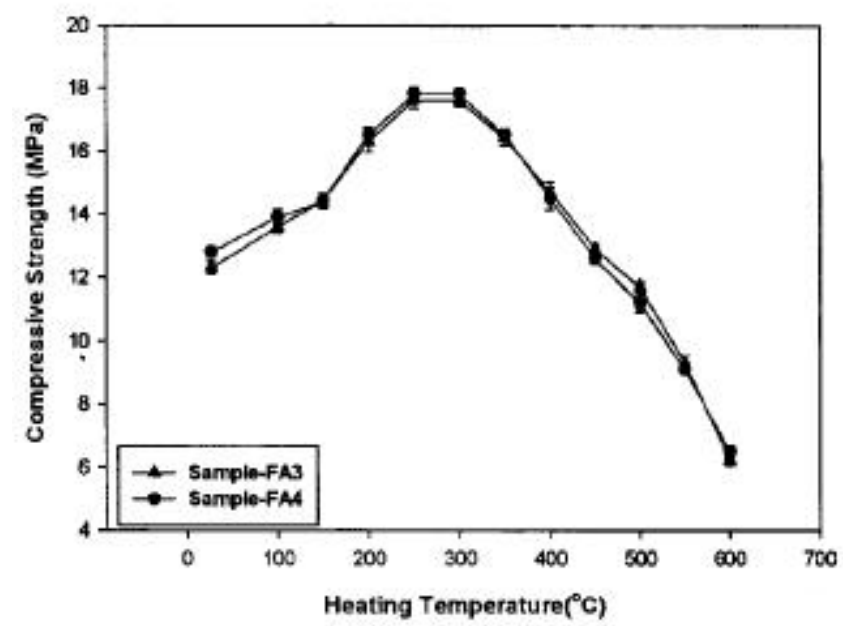

Figure 4. Effect of heating on the compressive strength of steam cured fly ash-lime compacts.
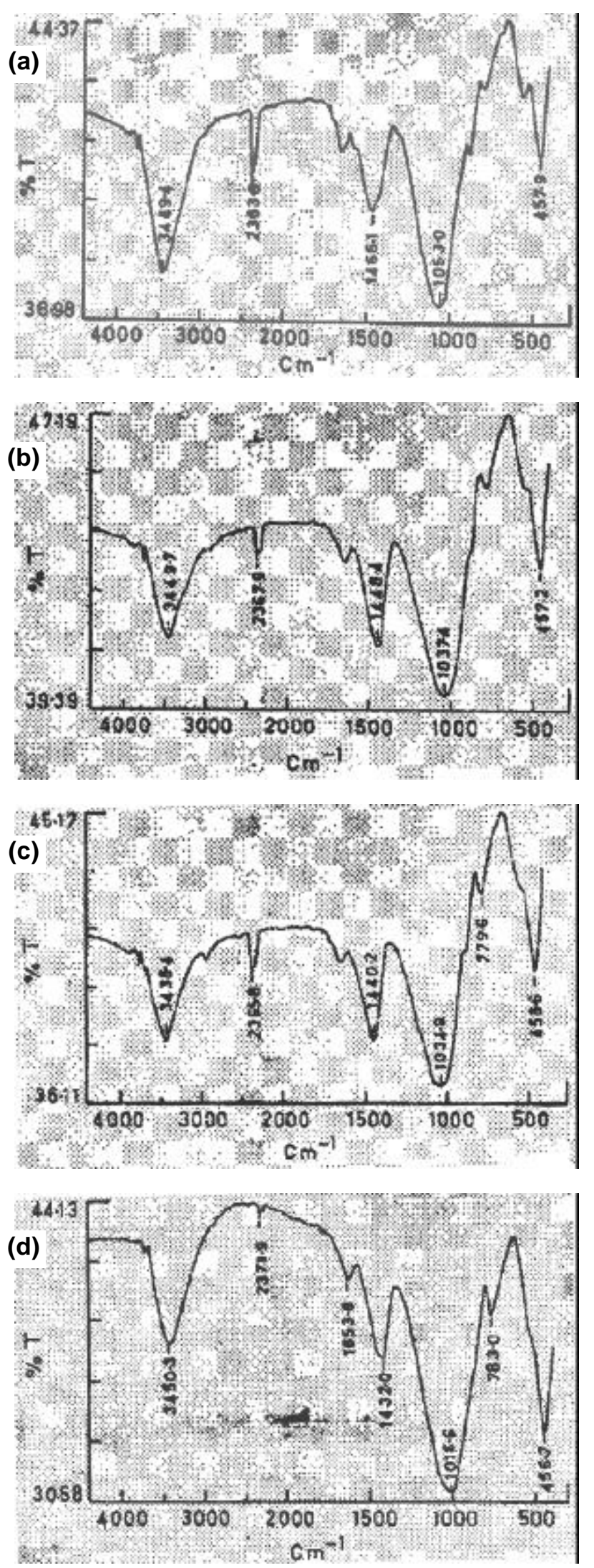

Figure 5. FTIR spectra of fly ash-lime (9:1) compacts after (a) steam curing, (b) after heating at $300^{\circ} \mathrm{C}$, (c) after heating at $400^{\circ} \mathrm{C}$ and (d) after heating at $600^{\circ} \mathrm{C}$. 
FT-IR spectra of the samples vibration of $\mathrm{Si}-\mathrm{O}$ stretching frequency decreased with the increase in heating temperature. For the sample without any heat treatment it occurred at $1053 \mathrm{~cm}^{-1}$, at $1037.4 \mathrm{~cm}^{-1}$ after heating to $300^{\circ} \mathrm{C}$, at $1034.9 \mathrm{~cm}^{-1}$ after heating to $400^{\circ} \mathrm{C}$ and after heating to $600^{\circ} \mathrm{C}$ it was observed at $1016 \cdot 6 \mathrm{~cm}^{-1}$. It could be due to reduced influence of water molecules (as the concentration was reduced) on the oxygen atom of $\mathrm{Si}-\mathrm{O}$ bond as well as due to the increase in positive charge density as a result of the elimination of bonded water molecules. Similarly, vibration of Al-O stretching frequency more or less decreased with the increase in heating temperature. In the sample without heat treatment it was observed at $457.9 \mathrm{~cm}^{-1}$, at $457.2 \mathrm{~cm}^{-1}$ after heating to $300^{\circ} \mathrm{C}$, and at $456.7 \mathrm{~cm}^{-1}$ after heating to $600^{\circ} \mathrm{C}$. This also suggested the reduced pull on the $\mathrm{Al}-\mathrm{O}$ bond by the water molecules with the increase in heating. $\mathrm{O}-\mathrm{H}$ bending vibration was also observed to decrease with the increase

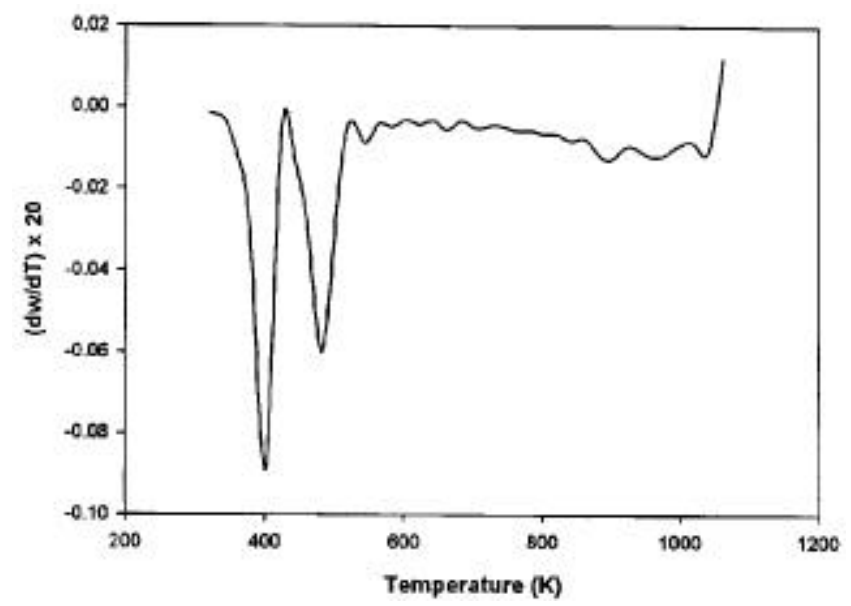

Figure 6. DTGA diagrams of fly ash-lime (9:1) compacts. in heating temperature. In case of sample with no additive this vibration was observed at $1466.1 \mathrm{~cm}^{-1}$, at $1448.4 \mathrm{~cm}^{-1}$ when heated to $300^{\circ} \mathrm{C}$, at $1440.2 \mathrm{~cm}^{-1}$ when heated to $400^{\circ} \mathrm{C}$ and at $1423 \mathrm{~cm}^{-1}$ after heating to $600^{\circ} \mathrm{C}$. $\mathrm{Ca}-\mathrm{O}$ stretching vibration for free $\mathrm{CaO}$ was evident only after firing at $400^{\circ} \mathrm{C}$ at $779.6 \mathrm{~cm}^{-1}$ and its frequency increased with the increase in firing temperature. $-\mathrm{OH}$ stretching vibration associated with $\mathrm{Ca}-\mathrm{O}$ bond increased with the increase in heating temperature indicating a drop in the bonding strength of the $-\mathrm{OH}$ group in $\mathrm{Ca}(\mathrm{OH})_{2}$.

\subsection{Kinetics of thermal dehydration of lime-fly ash hydrate compacts}

At the later stage the kinetics of thermal dehydration of different lime-fly ash hydrates was studied under nonisothermal conditions. This study was expected to give an idea of the relative stability of the different hydrate phases and the nature of stability at different elevated temperatures. Non-isothermal differential thermogravimetric studies with $9: 1$ fly ash-lime compacts were carried out to determine the kinetic parameters. The dehydration was assumed to follow an arbitrary order ' $n$ ' and the kinetic parameters have been evaluated assuming various values of $n$. The rate equation of thermal dehydration of the hydrated phases is given by

Hydrated phases $(s) \rightarrow$ dehydrated phases $(s)+$ water vapour.

The rate of dehydration of the hydrated phase is given by

$$
-\mathrm{d} w / \mathrm{d} t=k w .
$$

Incorporating into this equation, $k=A \cdot \exp (-E / R T)$ and heating rate, $h=\mathrm{d} T / \mathrm{d} t$ and rearranging we get

$$
[-(1 / w) \cdot(\mathrm{d} w / \mathrm{d} t)]=A / h \cdot \exp (-E / R T) .
$$

\begin{tabular}{|c|c|c|c|c|}
\hline & $1 \mathrm{Wt} \%$ & $2 \mathrm{Wt} \%$ & $3 \mathrm{Wt} \%$ & $4 \mathrm{Wt} \%$ \\
\hline \multicolumn{5}{|l|}{ A. Chemical compositions } \\
\hline $\mathrm{SiO}_{2}$ & $54 \cdot 30$ & $60 \cdot 20$ & $62 \cdot 72$ & $52 \cdot 00$ \\
\hline $\mathrm{Al}_{2} \mathrm{O}_{3}$ & $23 \cdot 30$ & $23 \cdot 90$ & $29 \cdot 93$ & $23 \cdot 00$ \\
\hline $\mathrm{Fe}_{2} \mathrm{O}_{3}$ & $8 \cdot 30$ & $7 \cdot 80$ & $2 \cdot 13$ & $2 \cdot 30$ \\
\hline $\mathrm{CaO}$ & 1.42 & $2 \cdot 06$ & $2 \cdot 33$ & $10 \cdot 50$ \\
\hline $\mathrm{MgO}$ & $0 \cdot 68$ & $0 \cdot 70$ & 0.72 & $3 \cdot 25$ \\
\hline LOI & $5 \cdot 80$ & $0 \cdot 35$ & $0 \cdot 52$ & $2 \cdot 50$ \\
\hline $\mathrm{Na}_{2} \mathrm{O}$ & 1.43 & 0.51 & $0 \cdot 19$ & $1 \cdot 33$ \\
\hline $\mathrm{K}_{2} \mathrm{O}$ & $1 \cdot 38$ & 0.73 & $0 \cdot 25$ & $1 \cdot 88$ \\
\hline $\mathrm{SO}_{3}$ & $0 \cdot 23$ & 1.97 & $0 \cdot 19$ & $0 \cdot 63$ \\
\hline $\mathrm{TiO}_{2}$ & 1.45 & $0 \cdot 42$ & 0.75 & 1.95 \\
\hline $\mathrm{Cl}$ & 0.02 & - & - & $0 \cdot 02$ \\
\hline $\mathrm{P}_{2} \mathrm{O}_{5}$ & - & - & - & - \\
\hline \multicolumn{5}{|l|}{ B. Physical properties } \\
\hline Bulk density $\left(\mathrm{g} / \mathrm{cm}^{3}\right)$ & 0.91 & $0 \cdot 82$ & 0.77 & $0 \cdot 84$ \\
\hline Specific gravity & $2 \cdot 21$ & $2 \cdot 12$ & $2 \cdot 10$ & $2 \cdot 12$ \\
\hline Surface area (Blain's, $\mathrm{cm}^{2} / \mathrm{g}$ ) & 3775 & 4120 & 4510 & 5172 \\
\hline
\end{tabular}

Table 1. Physico-chemical properties of fly ash samples. 
The rate equation may also be expressed in terms of fractional conversion, $X$ and reaction order, $n$, as follows,

$$
\begin{aligned}
& {\left[x=\left(w_{\mathrm{o}}-w\right) /\left(w_{\mathrm{o}}-w_{\alpha}\right)\right]} \\
& -\mathrm{d} x / \mathrm{d} t=k(1-x)^{n} .
\end{aligned}
$$

Incorporating expression of heating rate, $h$ and rate constant, $k$, into the above equation, rearranging and integrating, the following equation is obtained

$$
\int_{0}^{X} \mathrm{~d} x /(1-x)^{n}=A / h \int_{0}^{T} \exp (-E / R T) \mathrm{d} T .
$$

Among several approximate solutions the equation given by Coats and Redfern (1964) are the most commonly used and are as follows

$$
\begin{aligned}
& \operatorname{Ln}\left[\{-\operatorname{Ln}(1-x)\} / T^{2}\right]= \\
& \quad \operatorname{Ln}[A R / h E(1-2 R T / E)]-E / R T \quad \text { for } n=1 \cdot 0, \\
& \operatorname{Ln}\left[-\operatorname{Ln}\left\{1-(1-x)^{1-\mathrm{n}}\right\} /(1-n) T^{2}\right]= \\
& \quad \operatorname{Ln}[A R / h E(1-2 R T / E)]-E / R T \text { for } n \neq 1 \cdot 0 .
\end{aligned}
$$

and

Therefore, a plot of $\operatorname{Ln}\left[-\operatorname{Ln}(1-x) / T^{2}\right]$ vs $1 / T$ for $n=1 \cdot 0$ and $\operatorname{Ln}\left[-\operatorname{Ln}\left\{1-(1-x)^{1-n}\right\} /(1-n) T^{2}\right]$ vs $1 / T$ for $n \neq 1.0$ gives us the value of $E$ for both the methods.

The dehydration process takes place mainly at two different temperature ranges as two peaks were formed at $403 \mathrm{~K}$ and $533 \mathrm{~K}$, respectively in the DTGA diagram (figure 6). This might be due to the difference in relative stability of the different hydrated phases formed by the interaction between lime and fly ash.

The order of the reactions and the activation energies in two different temperature ranges were calculated and the results are summarized in tables 2 and 3 .

From the results it was evident that the dehydration at the first peak follows mostly 1 st order reaction with an activation energy of $45.5692 \mathrm{~kJ} / \mathrm{mole}$ which might be taken as the bond strength of the calcium silicate/aluminate hydrates formed in the cured fly ash-lime compacts within this temperature range. The dehydration at the second stage as indicated by the second peak followed mostly 2 nd order reaction with an approximate activation energy of $57.765 \mathrm{~kJ} /$ mole. Therefore, dehydration at the two temperature zones takes place by different mecha-

Table 2. Order of the reaction and activation energy for the dehydration reaction.

\begin{tabular}{lccc}
\hline$n$ & $E(\mathrm{~kJ} / \mathrm{mole})$ & Standard error & $\begin{array}{c}\text { Correlation } \\
\text { coefficient }\end{array}$ \\
\hline 0.3 & 23.3474 & 1.7889 & 0.9453 \\
0.5 & 31.8384 & 1.6724 & 0.9474 \\
0.85 & 26.9656 & 1.4018 & 0.9484 \\
0.95 & 22.6456 & 1.2224 & 0.9447 \\
1.0 & 46.5692 & 0.5417 & 0.9972 \\
\hline
\end{tabular}

Temperature range: $323-483 \mathrm{~K}$. nisms. The creation of voids and channels as a result of dehydration at the first stage accelerates the rate of dehydration at the second stage.

\section{Conclusions}

(I) When the fly ash-lime compacts were subjected to elevated temperature, both physically and chemically absorbed molecules remaining in the compacted mass was lost progressively. Above $300^{\circ} \mathrm{C}$ free lime content started to increase in two different stages. This suggested different temperature stability zone of calcium silicate hydrates. The compressive strength of the compacts increased up to a temperature of $250^{\circ} \mathrm{C}$, which might be ascribed to the removal of loosely held mobile water from the structure. After this temperature compressive strength of the compacts decreased with the increase in temperature.

(II) From the FTIR spectra of the fly ash-lime sample during heating it was observed that the $\mathrm{Si}-\mathrm{O}$ and $\mathrm{Al}-\mathrm{O}$ stretching vibration frequency decreased with the increase in heating temperature, as a result of reduction in the water molecules from the silicate hydrate and aluminate hydrates which generally caused increase in the stretching vibration frequency on the $\mathrm{Si}-\mathrm{O}$ and $\mathrm{Al}-\mathrm{O}$ bonds. The bending vibration of bonded water molecules progressively decreased with the increase in heating temperature. The $\mathrm{Ca}-\mathrm{O}$ stretching vibration frequency of free $\mathrm{CaO}$ was not observed till $300^{\circ} \mathrm{C}$ and after that it increased with the increase in heating temperature. The stretching vibration of $-\mathrm{OH}$ bond associated with $\mathrm{Ca}(\mathrm{OH})_{2}$ increased with the increase in heating temperature due to reduction in concentration of water molecules.

(III) Kinetic study under non-isothermal conditions at two different temperature ranges, 403 and $533 \mathrm{~K}$, respectively (from thermogravimetry) revealed that dehydration at the first peak follows mostly 1 st order reaction with an activation energy of $46.5692 \mathrm{~kJ} /$ mole which might be taken as the bond strength of the calcium silicate/aluminate hydrates formed in the cured fly ash-lime compacts within this temperature range. The dehydration at the second stage as indicated by the second peak followed

Table 3. Order of the reaction and activation energy for the dehydration reaction.

\begin{tabular}{lccc}
\hline$n$ & $E(\mathrm{~kJ} / \mathrm{mole})$ & Standard error & $\begin{array}{c}\text { Correlation } \\
\text { coefficient }\end{array}$ \\
\hline $0 \cdot 3$ & $54 \cdot 5830$ & $0 \cdot 6243$ & 0.9952 \\
$0 \cdot 5$ & $51 \cdot 4794$ & $0 \cdot 5602$ & 0.9956 \\
$0 \cdot 85$ & $43 \cdot 4838$ & $0 \cdot 5007$ & 0.9951 \\
$0 \cdot 95$ & $36 \cdot 8726$ & $0 \cdot 4330$ & 0.9949 \\
$1 \cdot 0$ & $55 \cdot 7636$ & $0 \cdot 5389$ & 0.9965 \\
$1 \cdot 5$ & $65 \cdot 4195$ & $0 \cdot 4559$ & 0.9978 \\
$1 \cdot 75$ & $60 \cdot 4502$ & $0 \cdot 3851$ & 0.9984 \\
$2 \cdot 0$ & $57 \cdot 7648$ & $0 \cdot 3473$ & 0.9986 \\
\hline
\end{tabular}

Temperature range: $483-583 \mathrm{~K}$. 
mostly 2nd order reaction with an approximate activation energy of $57.7648 \mathrm{~kJ} / \mathrm{mole}$.

\section{References}

Barbier U 1986 Ind. Ital. Laterizi 4053

Basumajumdar A, Das A K, Bandyopadhyaya N and Maitra S 2005 Bull. Mater. Sci. 28131

Coats A W and Redfern J P 1964 Nature 20168

Hanna W C, Hicks T A and Saeger G A 1938 Bull. Am. Ceram Soc. Test. Mater. 9447

Hanna W C, Hicks T A and Saeger G A 1939 Proc. Am. Soc. Test. Mater. 39314
Kumar S 2002 Construction \& Building Materials 16519

Liu Q G, Fu Y J and Xiao Q G 1994 Guisuanyan Jianzhu Zhipin 3 27

Ma J R and Zhao X J 1993 Guisuanyan Jianzhu Zhipin 433

Ma W and Brown P W 1997 Cem. Concr. Res. 271237

Muntcan M, Paul F and Haret B 1987 Mater. Constr. 17226

Song J T, Yun S D, Ryan D W and Han K S 1996 J. Korean Ceram. Soc. 33154

Tsunematsu S, Inow N and Hara N 1987 Gypsum and Lime 211 362

Wang X, Yang N and Zhang B 1996 J. Chinese Ceram. Soc. 24 137

Watt J D and Thorne D J 1996 J. Appl. Chem. 15585

Zhu B X 1994 Guisuanyan Jianzhu Zhipin 112 